\title{
Intercomparison of Thermal Converters at NIM, NIST, PTB, SIRI, and VSL from 10 to $100 \mathrm{MHz}$
}

\author{
Joseph R. Kinard, Senior Member, IEEE, Zhen Zhen, De-xiang Huang, Gregorio Rebuldela, \\ Dieter Janik, and Jan de Vreede
}

\begin{abstract}
Coaxial thermal voltage converters have been intercompared among NIM, NIST, PTB, SIRI, and VSL in the frequency range from $10 \mathrm{MHz}$ to $100 \mathrm{MHz}$. The intercomparisons were made from 1988 through 1990 . This paper briefly describes the highly varied methods and underlying principles on which RF-dc difference determinations are based in each laboratory, the transport standards used, and the results of the intercomparisons. The results from the participating laboratories are in very good agreement; therefore, we believe that the determinations of RF-dc difference in this frequency range are very well established.
\end{abstract}

\section{INTRODUCTION}

$\mathrm{C}$ OAXIAL thermal voltage converters (TVC's) are commonly used for the measurement of voltage in the frequency range from $10 \mathrm{MHz}$ to $100 \mathrm{MHz}$. An intercomparison of RF-dc differences in this frequency range among the participating laboratories is particularly informative because the methods and hardware of the different laboratories differ significantly. The agreements among methods add considerable additional confidence to the process. In these intercomparisons, which were made in 1988 through 1990 , NIST-Gaithersburg was the pilot laboratory.

\section{Methods of Individual Laboratories}

\section{A. National Institute of Metrology (NIM)}

At NIM, TVC's have been constructed in a special way in order to achieve flat frequency response up to $1 \mathrm{GHz}$ without component compensation. In these special TVC's, the thermoelement is placed near the input connector, to measure the input current approximately, and the range resistor is connected to the shield [1].

The RF-dc differences of the TVC's have been determined to be less than several percent from $30 \mathrm{MHz}$ up to $1 \mathrm{GHz}$ by reference to a bolometer bridge with dual, thinfilm bolometers. This bolometer bridge was designed and

Manuscript received June 12, 1992; revised September 21, 1992.

J. R. Kinard is with the Electricity Division, National Institute of Standards and Technology, U.S. Dept. of Commerce, Technology Administra tion, Gaithersburg, MD 20899.

G. Rebuldela is with the Electromagnetic Fields Division, NIST, U.S Dept. of Commerce, Technology Administration, Boulder, CO 80303.

Z. Zhen is with the National Institute of Metrology, Beijing, P.R.C.

D.-X. Huang was with Shaoxing Industry Research Institute, Shaoxing, P.R.C.; he is presently with Ballantine Laboratories, Cedar Knolls, NJ 07927 . constructed at NIM. The analysis of the bolometer bridge errors is given in [2]. It was calibrated by conventional TVC's at $10 \mathrm{MHz}$ and compared to several other bolometer designs developed in China. The frequency response of the bolometer bridge was also compared to a microwave power standard from $300 \mathrm{MHz}$ up to $5 \mathrm{GHz}$ and was very flat above $30 \mathrm{MHz}$. The uncertainty of this NIM bolometer bridge is $< \pm 1 \%$ from $10 \mathrm{MHz}$ to $3 \mathrm{GHz}$ [2]. The special TVC's have also been compared to conventional TVC's at $100 \mathrm{MHz}$ and below.

\section{B. National Institute of Standards and Technology (NIST-Boulder)}

Two techniques have been used to establish the RF-dc differences of the NIST-Boulder working standard set of TVC's. The first of these involved the use of a bolometer bridge [3]. Although the bridge is not currently in use, the RF-dc differences and uncertainties derived from it have been confirmed by comparison with voltages assigned from impedance measurements made on impedance bridges and power measurements made with a microcalorimeter from $100 \mathrm{MHz}$ to $1 \mathrm{GHz}$. The second technique establishes the frequency response below 100 $\mathrm{MHz}$ experimentally and theoretically as described in [4] and [5], respectively. These results derived at low frequencies agree with the characterization of a 1-V TVC based on the bolometer bridge from $1 \mathrm{MHz}$ to $400 \mathrm{MHz}$. Working standard TVC's for determination of RF-dc difference from below $1 \mathrm{MHz}$ to $1000 \mathrm{MHz}$ have been characterized on the bases of the derivation of voltage from power and impedance measurements and theoretical predictions for TVC's directly.

\section{National Institute of Standards and Technology (NIST-Gaithersburg)}

Using low frequency standards and nearly frequencyindependent structures, the RF-dc differences of coaxial TVC's at NIST-G were determined up to $1 \mathrm{MHz}$ [4], [5]. Intercomparisons of nearly identical structures with different range resistors demonstrated frequency flatness of $\pm 5 \mathrm{ppm}$ out to $100 \mathrm{kHz}$ and of $\pm 10 \mathrm{ppm}$ out to $1 \mathrm{MHz}$. To extend the frequency range up to $100 \mathrm{MHz}$, TVC's having cylindrical, carbon-film range resistors of $1-5 \mathrm{k} \Omega$ were constructed using designs and materials chosen to permit detailed modeling and analysis. For these TVC's 
the major RF-dc difference contributions from each structural element or region of the TVC were theoretically and experimentally analyzed up to $100 \mathrm{MHz}$. The major contributions to RF-dc difference, which were range independent, were the voltage standing wave in the input connector structure and the current standing wave in the thermoelement section. Major range-dependent contributions were the transimpedance of the range resistor and skin effect of the overall structure. The comparator system used at NIST-G for these intercomparisons is described in [5].

\section{Physikalisch-Technische Bundesanstalt (PTB)}

At PTB, RF-dc transfer difference measurements in this frequency range are made in two steps. Because there is a separate setup at PTB for measuring the ac-dc transfer difference up to $1 \mathrm{MHz}$ with very small uncertainties, the RF-dc transfer difference is calculated from the RF-ac difference and the ac-dc difference at $100 \mathrm{kHz}$. The response of the device under test with RF voltage applied is compared with its response to an ac voltage of $100 \mathrm{kHz}$. For frequencies above $1 \mathrm{MHz}$, a commercial coaxial calorimeter of the dual-load type is used as the primary voltage standard. Using this standard, which contains two nearly identical resistance mounts, the RF voltage is compared with an equivalent, adjustable dc voltage. The effective efficiency and the input conductance of the calorimeter have been determined as a function of frequency up to 1 $\mathrm{GHz}$. From these quantities, RF voltage has been derived in terms of power and impedance standards. The automated primary voltage standard for voltages between $0.2 \mathrm{~V}$ and $1 \mathrm{~V}$ is described in [6].

For the RF-dc transfer difference calibration of thermal converters in the range between $0.5 \mathrm{~V}$ and $10 \mathrm{~V}$ and the frequency range up to $100 \mathrm{MHz}$ an automated measuring system is used [7]. The set of working standards between $0.5 \mathrm{~V}$ and $10 \mathrm{~V}$ is calibrated with a step-up procedure starting with the $1-V$ converter which was calibrated by reference to the primary standard.

\section{E. Shaoxing Industry Research Institute (SIRI)}

At SIRI, the RF-dc differences of TVC's have been determined by theoretical calculations and experimental analysis [8]. Standard TVC's ranging from $0.5 \mathrm{~V}$ to $5 \mathrm{~V}$ have been measured by thin-film bolometers [2], [3] from $30 \mathrm{MHz}$ up to $300 \mathrm{MHz}$. For frequencies above $1 \mathrm{MHz}$, an empirical equation

$$
d=d_{0}+A \sqrt{f}+B f^{2}
$$

was used to make a nonlinear fit employing the leastsquares method. Here $d$ was RF-dc difference, $d_{0}$ was the ac-dc difference at audio frequency, $A$ was a constant determined from the regression and was related to skin effect, and $B$ was a constant determined from the regression and was related to the distributed inductance and capacitance. Thus the RF-dc differences from $100 \mathrm{kHz}$ to $100 \mathrm{MHz}$ for individual TVC's were determined.
Direct comparisons between adjacent ranges confirmed this modelling [9]. Additional confirmation of these primary TVC's was obtained by comparison with UHF, thinfilm multijunction thermal converters having RF-dc differences $<0.5 \%$ from $10 \mathrm{~Hz}$ to $1 \mathrm{GHz}$, and by comparison with TVC's having multifilar ground-lead compensation and also having RF-dc differences $<0.5 \%$ from $10 \mathrm{~Hz}$ to $300 \mathrm{MHz}$. For example, the RF-dc differences of one $10-\mathrm{V}$ commercial transport TVC, supplied by NIST-G, as measured by SIRI were expressed as

$$
d=-3.54 \times 10^{-3} \sqrt{f}-1.756 \times 10^{-4} f^{2}
$$

with $f$ in $\mathrm{MHz}$ and $d$ in $\%$, for frequencies from $10 \mathrm{MHz}$ to $100 \mathrm{MHz}$.

\section{F. Van Swinden Laboratory (VSL)}

In VSL, the RF-dc difference standards above $1 \mathrm{MHz}$ have been characterized in terms of a set of calculable standards and can be used up to $30 \mathrm{MHz}$ [10]. Recently, a new set of 4-V standards, with smaller but not necessarily negligible RF-dc differences, was constructed for use up to $100 \mathrm{MHz}$ [11]. All standards are provided with type- $\mathrm{N}$ male connectors and the symmetry plane of a type- $\mathbf{N}$ tee is taken as the plane of reference. In the automated measurement system, each thermoelement output is amplified and then the difference between the outputs is amplified. The RF-dc differences of each converter have been calculated and intercomparisons between TVC's yield good agreement within the combined uncertainties. However, since the VSL standard TVC's were more or less identical, there may have been undetected systematic errors, such as internal reflections within the devices, which have not yet been taken into account and which will be the subject of further study.

\section{Transport Standards}

The transport standards used in this intercomparison were TVC's of two basic types. The first type contained three versions of commercially manufactured, coaxial TVC's which consisted of one $1-V$, two $5-\mathrm{V}$, and two $10-\mathrm{V}$ ranges. They contained UHF-pattern thermoelements, internal shield structures, and conventional series resistors and were supplied by NIST-G. The second type of transport standard was a VSL-constructed and supplied coaxial, 4-V TVC containing a UHF-pattern thermoelement with a thin, straight wire for the series resistor [10]. The commercial TVC's were mounted with type- 874 connectors, and all measurements were referred to a plane of reference located at the center of a type-874 tee structure [12]. The VSL TVC has a type-N connector, so adjustments for the transmission line effect in the input connector structure were made to the data on the VSL TVC. Adjustments were also made to the measured results at NIM and SIRI in order to account for the L16G-type connector, equivalent to the type- $\mathrm{N}$ but manufactured in China to SI dimensions, used on their standard TVC's. 


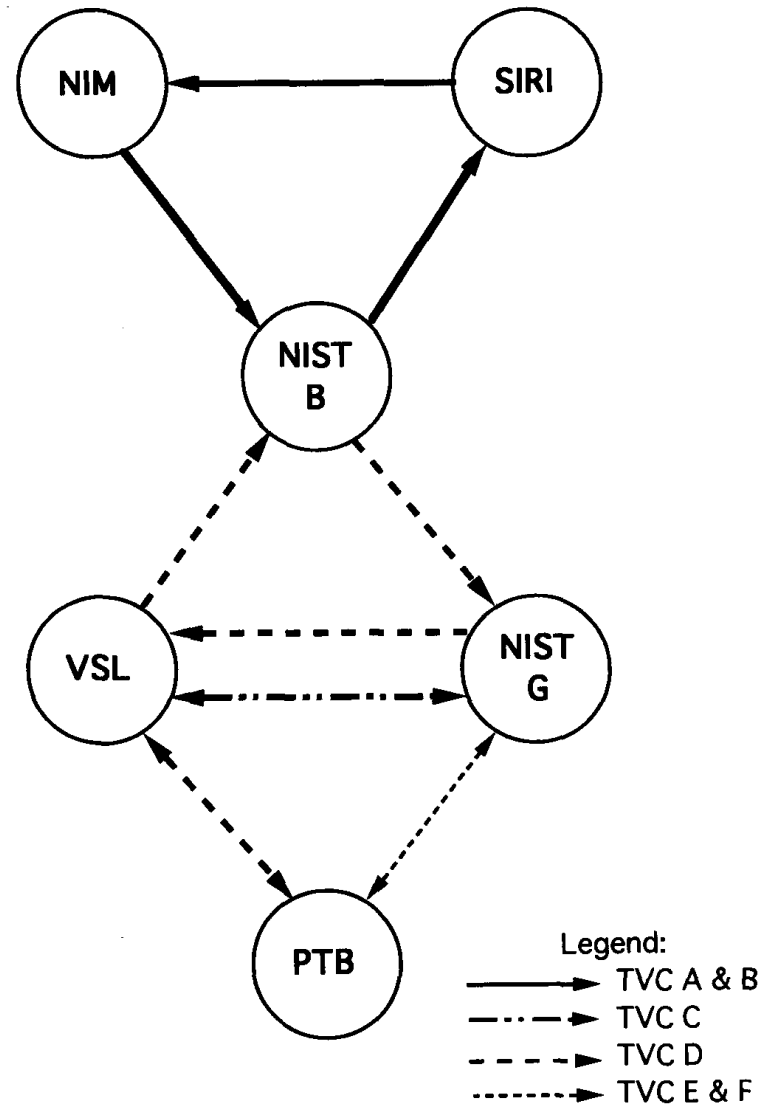

Fig. 1. Routes taken by the various TVC's used in the intercomparison.

\section{RESUlts}

The results include values for all of the types of TVC's even though not every TVC went to every laboratory. The routes taken by the various TVC's are shown in Fig. 1, and were chosen entirely on the basis of convenience and the availability of the TVC's.

The results reported by each laboratory were adjusted to remove the TVC-to-TVC variations and averaged to produce a representative value for that laboratory at each frequency. The representative values, or deviations, for all the laboratories at each frequency, were averaged and expressed relative to that overall average which was indicated as $0 \%$ RF-dc difference. These data are plotted in Fig. 2 and are given in Table I, along with $2 \sigma$ uncertainties, number of points contributed, standard deviations of the average values, and spans of the average values.

\section{CONCLUSION}

The methods used to determine RF-dc difference and the designs and construction of the primary TVC's of the different laboratories were very different. Every laboratory made both theoretical calculations and measurements to characterize their standards, but some made determi-
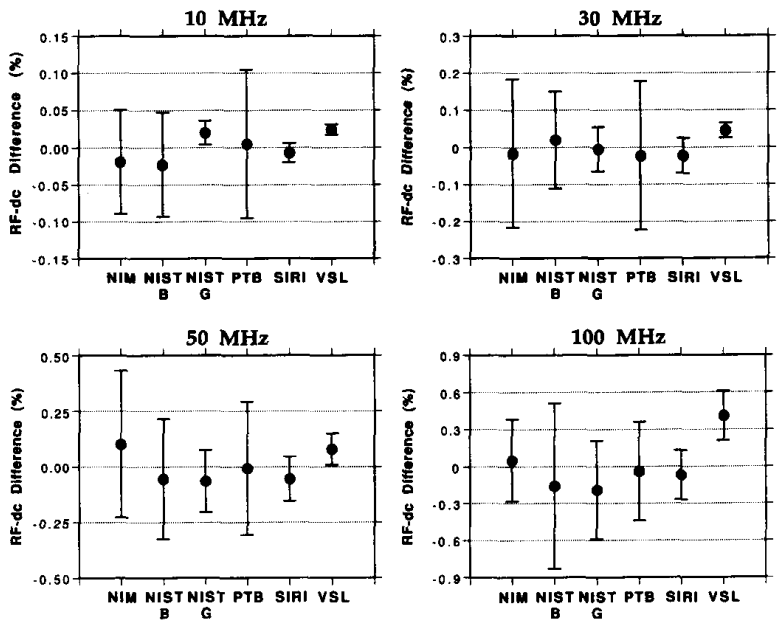

Fig. 2. Results of the intercomparison plotted with the overall average, calculated as described in the text, shown as 0\% RF-dc difference. Error bars represent $\pm 2 \sigma$ uncertainties.

TABLE I SUMMARY OF RF-DC DIFFERENCE INTERCOMPARISONS (\%)

\begin{tabular}{lcccc}
\hline & $10 \mathrm{MHz}$ & $30 \mathrm{MHz}$ & $50 \mathrm{MHz}$ & $100 \mathrm{MHz}$ \\
\hline Relative to Average Value & & & & \\
NIST-G & +0.020 & -0.005 & -0.064 & -0.19 \\
NIST-B & -0.023 & +0.020 & -0.055 & -0.16 \\
NIM & -0.019 & -0.016 & +0.102 & +0.05 \\
PTB & +0.005 & -0.023 & -0.007 & -0.04 \\
SIRI & -0.007 & -0.023 & -0.054 & -0.07 \\
VSL & +0.024 & +0.045 & +0.079 & +0.41 \\
2 $\sigma$ Uncertainties & & & & \\
NIST-G & 0.016 & 0.06 & 0.14 & 0.40 \\
NIST-B & 0.07 & 0.13 & 0.27 & 0.67 \\
NIM & 0.07 & 0.20 & 0.33 & 0.33 \\
PTB & 0.10 & 0.20 & 0.30 & 0.40 \\
SIRI & 0.013 & 0.047 & 0.10 & 0.20 \\
VSL & 0.007 & 0.02 & 0.07 & 0.20 \\
Number of Points Contributed & & & \\
NIST-G & 4 & 4 & 4 & 4 \\
NIST-B & 3 & 3 & 3 & 3 \\
NIM & 1 & 1 & 1 & 1 \\
PTB & 3 & 3 & 3 & 3 \\
SIRI & 2 & 2 & 2 & 2 \\
VSL & 2 & 2 & 2 & 2 \\
Standard Deviation of & & & & \\
Average Values & 0.02 & 0.027 & 0.073 & 0.22 \\
Span of Average Values & 0.047 & 0.068 & 0.166 & 0.60 \\
\hline
\end{tabular}

nations based primarily on theoretical analysis and some primarily on measurements. Some started from low-frequency references, while some began with high-frequency references. Some based their work on reference standards with flat frequency response, and some tried carefully to characterize frequency response.

In view of these variations in methods, the very good overall agreements among the participating laboratories are quite significant. The uncertainty bars of nearly every laboratory cross the average line, and the uncertainty bars of most laboratories overlap. These intercomparisons 
show that the determinations of RF-dc difference in the $10-100 \mathrm{MHz}$ range are very well established.

\section{REFERENCES}

[1] Z. Zhen, L.-J. Wang, J.-L. Yan, and S.-L. Weng, "Precise RF voltage standard using a coaxial thermal voltage converter up to 1000 MHz," IMEKO XI, Metrology, p. 519, Oct. 1988.

[2] L.-J. Wang, Z. Zhen, C.-L. Guo, and J.-L. Yan, "A precision voltage standard at RF and microwave frequencies," ACTA Metrologica Sinica, vol. 1, no. 1, 1981 .

[3] M. C. Selby and L. F. Behrent, "A bolometer bridge for standard izing radio-frequency voltmeters,' Natl. Bur. Stand. (U.S.) J. Res., RP2055, vol. 44, Jan. 1950.

[4] F. L. Hermach and E. S. Williams, "Thermal voltage converters for accurate voltage measurements to 30 megacycles per second," AIEE Trans. (Comm. Electron.), vol. 79, pp. 200-206, July 1960.

[5] J. R. Kinard and T.-X. Cai, "Determination of ac-dc difference in the 0.1-100 $\mathrm{MHz}$ frequency range," IEEE Trans. Instrum. Meas., vol. 38, pp. 367, Apr. 1989.
[6] H. Gierke, L. Grno, D. Janik, and K. Münter, "Automatic rf voltage calibration with a primary voltage standard up to $1 \mathrm{GHz}$, " $C P E M$ ' 92 Digest, pp. 383-384, 1992.

[7] D. Janik, K. Münter, and F. H. Lou, "Automatisierung des hochfrequenz-spannungsmeßplatzes der PTB, " Fortschritte in der Hochfrequenzmeßtechnik, PTB Bericht E-38, pp. 3-20, 1990.

[8] D.-X. Huang, M.-L. Chen, and S.-Z. He, "RF-dc differences of coaxial thermal standards," IEEE Trans. Instrum. Meas., vol. 39, pp. 313-317, Apr. 1990.

[9] D.-X. Huang and S.-Z. He, "Experimental studies of the rf-dc differences of voltage standards," IEEE Trans. Instrum. Meas., vol. 39, pp. 10-14, Feb. 1990.

[10] M. Nomair and K. J. P. M. Harmans, "High accuracy calculable acdc transfer standards for the LF-30 MHz frequency range," IEEE Trans. Instrum. Meas., vol. 38, pp. 342-345, Apr. 1989.

[11] M. Nomair and K. J. P. M. Harmans, "A high accuracy calculable ac-dc transfer standard," VSL Report ES-88-04 (implementation in annex), 1989.

[12] D.-X. Huang, J. R. Kinard, and G. Rebuldela, "RF-dc differences of thermal voltage converters arising from input connectors," IEEE Trans. Instrum. Meas., vol. 40, pp. 360-365, Apr. 1991. 